\title{
Dostoiévski e Púchkin
}

\section{Aurora Bernardini ${ }^{1}$}

Resumo: Neste texto são apresentadas algumas das semelhanças e diferenças que existem na vida, formação e atividade literária de A.S. Púchkin e F. M. Dostoiévski, baseadas - primeiramente - nas pesquisas de dois críticos literários especialistas na análise bio-bibliográfica dos autores considerados. São eles, respectivamente H. Troyat e L. Grossman. Em segundo lugar, são focalizadas as características gerais dominantes na obra dos dois escritores e, com base no Discurso proferido por Dostoiévski em Moscou, em 8 de junho de 1880, por ocasião da inauguração do monumento a Aleksandr Púchkin, são ressaltadas dessemelhanças entre eles.

Palavras-chave: Dostoiévski e Púchkin; semelhanças e diferenças. Discurso de Dostoiévski sobre Púchkin.

Abstract: In our text we intend to present differences and similarities which exist in A.S. Puchkin's and F.M. Dostoievski's life, education and literary activities such as they were researched by critics like H. Troyat and L. Grossman. At the same time we make evident certain dominants in the work of both writers focusing Dostoievski's Discourse on Puchkin, pronounced on june, $8^{\text {th }}, 1880$.

Keywords: Dostoievski, Puchkin, similarities and differences. Dostoievski's Discourse on Puchkin.

Curiosamente, no começo do discurso proferido em Moscou em 8 de junho de 1880, por ocasião da inauguração do monumento a Aleksandr Púchkin (1799-1837), Fiódor Dostoiévski ( 1821-1881), ao explicitar o primeiro período da atividade de Púchkin, embora nele o poeta "já houvesse manifestado a independência de seu gênio", relaciona nele também as leituras dos poetas europeus: Parny, Chénier e principalmente Byron, que o teriam influenciado até o fim de sua vida. A essa lista, Henry Troyat - que, pelo que consta de seu alentado livro Pouchkine teria tido acesso à biblioteca pessoal do poeta - acrescenta uma série de autores. Púchkin, exilado em Mikhailóvskoie (1824 ),

\footnotetext{
${ }^{1}$ Professora Titular do Programa de Pós-graduação em Literatura e Cultura Russa do Departamento de Letras Orientais da Faculdade de Filosofia, Letras e Ciências Humanas da Universidade de São Paulo (DLO - FFLCH/USP).
} 
sob a desajeitada guarda paterna, ao mesmo tempo em que recorda, com a babá ainda viva, os contos da infância (Troyat, 1953, 371-73):

Sais-tu quelles sont mes occupations? Avant le déjuener, j' escris des notes. Je déjeune tard. Après le déjeuner, je monte a cheval. Le soir, j' écoute les contes de ma nounou et corrige ainsi les défauts de ma maudite éducation! Quelle merveille ces contes! Chacun d' entre eux est um poème...

pede desesperadamente ao irmão:

"Des vers, des vers, des vers! Conversations de Byron! Walter Scott! C' est la nourriture de l' âme... Voici pout toi une commission: Notes historiques sur Stenka Razine, unique personage poétique dans l' Histore Russe.(...) Envie moi les oevres de Lebrun, odes, elegies, etc....(...) Mémoirs de Fouché, Sismondi ( Litterature), Schlegel (Dramaturgie)...La Vie d' Emelka Pougatchev;le Voyage en Tauride de Mouraviev. (... ) La Bible! la Bible! Mais em français, absolument!

Si possible envie moi le dernier Genlis, Childe Harold, Lamartine...les oeuvres dramatiques de Schiller, Don Juan... et Le Courier de Siberie”.

E a eles Troyaut acrescenta Dante, Goethe, Alfieri, Cervantes, Shakespeare Moor, Saadi, Petrarca, Milton, Tácito, Flaubert,1001 noites...

Por outro lado, outro crítico-biógrafo, Leonid Grossman, também perlustra a biblioteca de Dostoiévski, que nos mostra, em relação à de Púchkin, semelhanças e diferenças ( Não se esqueça de que, quando Púchkin morreu, Dostoiévski tinha 16 anos e que sobreviveu-lhe 44 anos), ou seja, grosso modo, metade da vida dele ultrapassou a de Púchkin. Entre os pré-românticos, os românticos e os góticos lidos por Dostoiévski: Schiller (Maria Stuart), Ann Radcliffe, Byron, Victor Hugo (Os miseráveis), Balzac, George Sand, Sterne, Scott, Balzac, Dickens, Sue (O judeu errante), Soulier (Memórias do Diabo), Dumas (O conde de Montecristo, Os três mosqueteiros), Mil e uma noites, Hoffman, Merimé, Daudet, Poe e, entre os russos, Tiútchev (acima de Heine), Tolstói (Guerra e paz; Infância, Adolescência, Mocidade), Turguênev (Pais e Filhos), Púchkin (contos), Gógol, Lermontov, Karamzin (Pobre Lisa)...

Semelhanças e diferenças há muitas para apontar, mas pelo esboço dessas primeiras leituras, vê-se claramente a orientação dominante de cada um: poesia para Púchkin e narrativa para Dostoiévski.

As primeiras semelhanças implicam a primeira infância: enjeitado pelos pais frívolos e mundanos, Aleksandr, o menino de traços africanos herdados do tataravô 
Abraão Petróvitch Aníbal (1696-1781), o famoso "Negro de Pedro, o Grande", procura abrigo junto à babá Arina Radiônovna, que o acalenta com as lendas folclóricas e as crenças dos humildes camponeses.

O menino Fiódor sofre os rigores da inclemente educação paterna e, com a mãe demasiado fraca para poder ampará-lo, procura abrigo no jardim do hospital onde o pai clinicava, em contato com doentes de toda espécie.

Ambos amadurecem pelas leituras e ambos têm como lema: " esticar até o extremo, em minha vida, o que vocês só têm coragem de esticar até a metade". Ambos foram amigos de conspiradores- os decabristas e os membros do círculo de Petrachévski, respectivamente, e, sem conspirar, foram exilados e "perdoados", mas ambos fizeram com sua obra, pela causa da liberdade, muito mais do que qualquer conspirador, com sua vida.

\section{Formação}

Púchkin estudou francês, alemão, literatura russa, economia política e foi autodidata em poesia, teatro ( Shakespeare), literaturas estrangeiras, e filosofia (francesa, principalmente), num curso que durou seis anos, correspondente ao que se poderia chamar Liceu, justamente no Liceu de Tsárskoie Seló, e sua formação foi eminentemente literária. Ele sentiu o apelo da poesia aos doze anos e foi o poeta russo por excelência, guardando ritmo e rima segundo o modelo introduzido por Jukóvski, que, a partir das traduções que fez de obras de Gray, Bürger, Uhland, Schiller e Goethe, firmará na literatura russa o uso da métrica baseada na sequência de "pés", sendo que sua distribuição e a distribuição dos acentos no verso serão regidas pelo esquema do metro correspondente. Em meados do século XVIII, Lomonóssov e Trediakóvski já haviam experimentado esse sistema denominado sílabo-tônico (diferente do silábico francês), que tem raízes na metrificação greco-latina clássica e também é usado na poesia alemã e inglesa. Uma vez que em russo o acento de intensidade desempenha um papel importante, como no inglês e no alemão, era natural que esse tipo de metrificação se firmasse na Rússia como sendo o mais apropriado para sua expressão poética. Os "pés" usados na poesia russa são, para os metros binários, o jambo (sílaba breve, sílaba longa) e o troqueu (sílaba longa, sílaba breve); para os metros ternários, o dátilo (uma sílaba longa e duas breves), o anapesto (duas sílabas breves e uma longa) e o anfibráquio (sílaba breve, sílaba longa e sílaba breve). Foi justamente Aleksandr 
Púchkin quem consagrou esse novo modelo, levado adiante por seus sucessores, inspirando-se, em algumas de suas composições, nos poemas épicos e nas canções da poesia popular medieval russa e inovando ele mesmo, ao introduzir alterações no metro nos momentos de grande intensidade do sentido. Dos metros binários, o jâmbico é o mais corrente em russo, sendo que representa $84 \%$ da produção poética de Púchkin. Em tetrâmetros jâmbicos ele compôs a maioria de seus versos, reservando o pentâmetro para o Boris Godunov e para as "pequenas tragédias": Mozart e Salieri, Festim durante a Peste, O Cavaleiro Avaro e O Convidado de Pedra. Só como curiosidade deve-se observar que as tentativas de Púchkin de compor em versos mais livres foram rejeitadas pelo público da época, tendo ele que reescrever poemas e colocá-los no ritmo e nas rimas esperadas. Em sua prosa, fantástica, histórica ou realística (A dama de espadas, $A$ filha do capitão, Contos de Biélkin) conservará a mesma autenticidade, às vezes chocante e, mutatis mutandis, a mesma fluência e harmonia de sua poesia.

Já a formação de Dostoiévski foi em engenharia, e sua leitura, as obras da literatura mundial, perpetrada nas barracas e nos acampamentos de Peterhoff (a teoria da poesia deixando lugar, para ele, à jovem crítica russa), formação e leituras essas que viriam a marcar seu estilo e as estruturas complexas de suas composições.

Se para ambos a função do artista é reproduzir a verdade, a forma de fazê-lo foi bastante diferente. Em Púchkin o ritmo flui harmoniosamente (mesmo em suas obras em prosa), em Dostoiévski o fluir do ritmo é atormentado, retorcido, convulso. Se no primeiro é a imagem, o léxico, o som que dominam (Quer escrever prosa? - teria dito Púchkin a um seu interlocutor - leia poesia), no segundo - como foi consagrado por Bakhtin, são as ideias, melhor, a polifonia das ideias. Mas que ideias são essas? Filosóficas, psicológicas, parapsicológicas, de folhetim policial, de quadros de costumes, de relatórios de crimes (Crime e castigo), políticas (Os demônios), em espiral ( obók, O menino e a árvore de Natal, Sonho de um homem ridículo, Ela era doce e humilde...)

Se os protagonistas das obras em prosa de Púchkin ou são personagens históricos (A revolta de Pugatchôv, A filha do capitão) ou figuras do dia a dia, no campo (Os contos de Biélkin), ou personagens da nobreza, (A dama de espadas, Dubróvski, O negro de Pedro, o Grande), os de Dostoiévski são verdadeiros Leitmotive que voltam em situações que se repetem nas diferentes obras: pensadores e sonhadores (Noites brancas, O sonho do titio, Míchkin, Ivan); jovens ultrajadas (Várienka, Humilhados e ofendidos, A árvore de Natal, $O$ idiota); os voluptuosos ( $O$ idiota, Os 
irmãos Karamazov); o palhaço voluntário (Uma história enfadonha, Polzunkov), sósias, parasitas, criados mentirosos etc.

É numa particularidade do estilo que se encontra na "poesia" de Dostoiévski. Ao escrever O senhor Prokhartchin, por exemplo, como observa Bóris Schnaiderman, Dostoiévski fez uso da linguagem hirta e espinhosa que o nome do protagonista sugere, algo como as Rimas petrosas de Dante.

Ambos, entretanto, possuem uma característica que é dada apenas a alguns grandes escritores: são capazes de diferenciar as vozes de seus protagonistas. Os mercadores de Shakespeare, no fundo são ingleses e não venezianos. Já os salteadores de Púchkin são alemães, são de onde forem, originariamente -- diz Troyat, na obra mencionada. "Apenas Púchkin" - diz Dostoévski em seu discurso - "entre todos os poetas do mundo, possui o dom de encarnar-se completamente em cada nacionalidade estrangeira. Eis a cena do Fausto, eis o cavaleiro avaro e o festim durante a peste!"

Mas analisemos mais de perto certo trecho do discurso: “Вспомните странные стихи:

\section{Однажды странствуя среди люди}

дикой

Это почти буквальное переложение первых трех страниц из странной мистической книги, написанной в прозе, одного древнего английского религиозного сектатора, - но разве это только переложение? В грустной и восторженной музыке этих стихов чувствуется самая душа северного протестантизма, английского ересиарха, безбрежного мистика, с его тупым, мрачным и непреоборимым стремлением и со всем безудержем мистического мечтания. Читая эти странные стихи, вам как бы слышится дух веков реформации, вам понятен становится этот воинственный огонь начинавшегося протестантизма, понятна становится, наконец, самая история, и не мыслью только, а как будто вы сами там были, прошли мимо вооруженного стана сектантов, пели с ними их гимны, плакали с ними в их мистических восторгах и веровали вместе с ними в то, во что они поверили. Кстати: вот рядом с этим религиозным мистицизмом религиозные же строфы из Корана или «Подражания Корану»: разве тут не мусульманин, разве это не самый дух Корана и меч его, простодушная величавость веры и грозная кровавая сила еe? А вот и древний мир, 
вот «Египетские ночи», вот эти земные боги, севшие над народом своим богами, уже презирающие гений народный и стремления его, уже не верящие в него более, ставшие впрямь уединенными богами и обезумевшие в отъединении своем, в предсмертной скуке своей и тоске тешащие себя фантастическими зверствами, сладострастием насекомых, сладострастием пауковой самки, съедающей своего самца. Нет, положительно скажу, не было поэта с такою всемирною отзывчивостью, как Пушкин, и не в одной только отзывчивости тут дело, а в изумляющей глубине ее, а в перевоплощении своего духа в дух чужих народов, перевоплощении почти совершенном, а потому и чудесном, потому что нигде ни в каком поэте целого мира такого явления не повторилось. Это только у Пушкина, и в этом смысле, повторяю, он явление невиданное и неслыханное, а по-нашему, и пророческое, ибо... ибо тут-то и выразилась наиболее его национальная русская сила, выразилась именно народность его поэзии, народность в дальнейшем своем развитии, народность нашего будущего, таящегося уже в настоящем, и выразилась пророчески. Ибо что такое сила духа русской народности как не стремление ее в конечных целях своих ко всемирности и ко всечеловечности? Став вполне народным поэтом, Пушкин тотчас же, как только прикоснулся к силе народной, так уже и предчувствует великое грядущее назначение этой силы. Тут он угадчик, тут он пророк.”

"Justamente aqui, nessa qualidade, encontra ao máximo expressão essa sua força russa nacional, o caráter popular de sua poesia, de sua evolução, do porvir de todo o povo russo: nisso está seu caráter profético. Porquê, o que é a força do espírito do povo russo se não a sua aspiração, em sua meta última, à universalidade e à humanidade? Mal se tornou poeta popular, mal esteve em contato com a força do povo, Púchkin sentiu imediatamente a grande futura missão dessa força."

Aqui está a ideia latente de Dostoiévski que emerge, finalmente, por entre as muitas vozes de Púchkin:

"Os futuros russos, compreenderão todos... que se tornar um verdadeiro russo significará precisamente aspirar à definitiva reconciliação das contradições europeias, mostrar a saída à tristeza europeia: o ânimo russo, profundamente humano, saberá abraçar com amor fraterno todos os nossos irmãos e, no fim, quem sabe, dirá a palavra definitiva da grande harmonia universal, do acordo fraterno definitivo de todas as raças, segundo a lei evangélica de Cristo!"”

Conforme foi dito, é como se Dostoiévski tivesse vivido duas vidas consecutivas, em relação a Púchkin - e ele pôde, portanto, dar prosseguimento àquilo 
que a morte prematura, a época e a situação negaram a Púchkin, havendo, entretanto, para este, em relação a Dostoiévski, duas barreiras intransponíveis. Refiro-me aqui, no caso de Dostoiévski, em primeiro lugar, ao lado da aproximação consciente à dinastia imperial ("Dostoiévski” - escreve Vólguin “por princípio, não queria separar o czar do povo, considerando que idealmente, o primeiro deve ser a encarnação do espírito popular”) - coisa à qual Púchkin, mesmo em sua situação ambígua de vítima e protejé, jamais teria chegado.

Em segundo lugar, à sua visão historicamente utópica quanto à missão universal, evangélica, da Rússia, que Púchkin, cujo caráter, digamos - mais blasé e não preocupado com a religiosidade oficial, fez com que ele chegasse mais desencantadamente a outras perspectivas de futuro.

Não se tratava para Púchkin da felicidade universal, mas, no limite, da obrigação que o indivíduo tem, por ser moral, de melhorar-se.

E aqui vai bem uma comparação irônica de Vólguin (2010):

"A Rússia é a ideia fixa de Dostoiévski. Por isso ele queria colocar no âmbito do espírito russo todo o sentido histórico mundial".

Já, quanto a Púchkin:

“O rus!” exclama Horácio. E o nosso poeta nacional (não só pelo “bon mot”!) responde alegremente, de pronto: “O Русь!” (“Ó Rússia!”). ${ }^{2}$

Mas, voltando a Dostoiévski e finalizando essa participação ao encontro "Dostoiévski: múltiplas perspectivas", aqui vai igualmente bem a conclusão de Boris Schnaiderman em "Dostoiévski através do tempo: o "romancista-filósofo", o público, a crítica", o primeiro ensaio do livro Turbilhão e semente - Ensaios sobre Dostoiévski e Bakhtin:

"Como explicar [por exemplo] certas páginas do Diário de um escritor, características por um chauvinismo grão-russo simplesmente intolerável à leitura e repassadas de ódio ora ao ocidental, em geral, ora ao judeu, ora a outras populações do Império? Como harmonizar um Dostoiévski "positivo" politicamente com a sua visão messiânica da Rússia? Quanto mais a crítica engajada em posições políticas de momento se dedica ao escritor, em busca de um aliado, menos compreensíveis se tornam certos aspectos de sua obra. Não, temos que deixar de lado todas essas manifestações imediatistas e utilitárias e voltar-nos para as grandes realizações já conseguidas pelos estudos dostoievskianos, marcados muitas vezes pela indagação e pela dúvida.

\footnotetext{
2 Epígrafe do segundo capítulo de Evguêni Oniêguin, de A. Púchkin. (Rus, ruris, el latim, no uso que Horácio faz do termo, signiifica "rusticidade").
} 
Mas, de indagação em indagação, a imagem de Dostoiévski, a princípio recortada grosseiramente em branco e preto, vai se colorindo de matizes cada vez mais opulentos e variados, cada vez mais fascinante em suas contradições e esfumaçamento."

\section{Referências bibliográficas}

DOSTOIÉVSKI, Fiódor. Obra completa em 30 tomos. Leningrado: Edição acadêmica, 1972-1990.

DOSTOIÉVSKI, Fiódor. “ O senhor Prokhartchin” ( trad. Bóris Schnaiderman) . São Paulo: Perspectiva, 1982

GOMIDE, Bruno Barreto ( org.) .Antologia do pensamento crítico russo ( 18021901). São Paulo: Editora 34, 2013.

GROSSMAN, Leonid. Dostoiévski artista. Rio de Janeiro: Civilização brasileira,1967.

LOGATTO, Ettore. Traduzione, Introduzione e Note. In PUSKIN, Aleksandr . Eugenio Onjeghin. Firenze: Sansoni,1922.

LOTMAN, I.M. Púchkin. São Petersburgo: Isskusstvo-SPB ,1995.

PÚCHKIN, A. S. Evguêni Oniéguin . Moscou: A.TR.I UM, 1991.

PÚCHKIN, Aleksandr. Púchkin: Prosa e Poesia. ( Tradução de Boris Schnaiderman e Nelson Ascher). São Paulo: editora 34, 1997.

PUSHKIN , Alexandr Eugênio Oneguin. ( Tradução de Dário Moreira de Castro Alves). Rio de Janeiro: Record, 2010.

SCHNAIDERMAN, Bóris. Dostoiévski, Prosa Poesia. São Paulo: Perspectiva, 1982.

SCHNAIDERMAN, Bóris.Turbilhão e semente - Ensaios sobre Dostoiévski e Bakhtin.São Paulo: Duas cidades, 1983.

TROYAT, Henri . Pouchkine - Biografie. Paris: Librairie Plon, 1953.

VOLGUIN, Igor." O retorno do bilhete - Paradóxos da auto-consciência nacional". ( Trad. Henady Malarenko) . Moscou: Grant, 2004 